\title{
Induction of Heparanase Gene Expression in Ventricular Myocardium of Rats with Isoproterenol-Induced Cardiac Hypertrophy
}

\author{
Keiichiro Kizaki, $\left.{ }^{*}, a, 1\right)$ Muneyoshi OKada, ${ }^{a}$ Ryoichi Ito, ${ }^{a}$ Kazuki Yoshioka, ${ }^{b}$ \\ Kazuyoshi Hashizume, ${ }^{c}$ Ken-ichiro Mutoh, ${ }^{b}$ and Yukio HarA ${ }^{a}$ \\ ${ }^{a}$ Department of Veterinary Pharmacology, School of Veterinary Medicine and Animal Sciences, Kitasato University; \\ ${ }^{b}$ Department of Veterinary Anatomy, School of Veterinary Medicine and Animal Sciences, Kitasato University; Towada, \\ Aomori 034-8628, Japan: and ${ }^{c}$ Laboratory of Veterinary Physiology, Department of Veterinary Medicine, Faculty of \\ Agriculture, Iwate University; Morioka, Iwate 020-8550, Japan.
}

Received August 15, 2005; accepted September 15, 2005; published online September 20, 2005

\begin{abstract}
Gene expression of heparanase, matrix metalloproteinases (MMP)-2 and MMP-9 were examined in ventricles after chronic treatment with isoproterenol (ISO) induced cardiac hypertrophy in rats. Rats were treated with ISO $(4 \mathrm{mg} / \mathrm{kg}$, intraperitoneal) twice daily for $4 \mathrm{~d}$. Ventricle weight of the heart and the ventricle weight/body weight ratio were increased respectively by $22 \%$ and $25 \%$ compared with control rats. Histology showed considerable cardiomyocyte hypertrophy in the ISO-treated rats in comparison to control rats. Northern blot hybridization revealed that heparanase and MMP-2 gene transcripts increased significantly in the ventricles of ISO-treated rats, whereas MMP-9 gene expression was not induced. Thus, heparanase and MMP-2 gene expressions are induced in the ventricle after chronic treatment with ISO, indicating that they might play an important role in development of ISO-induced cardiac hypertrophy.
\end{abstract}

Key words cardiac hypertrophy; heparanase; matrix metalloproteinase (MMP)

Heparanase is an endo- $\beta$-D-glucuronidase that degrades heparan sulfate side chains of heparan sulfate proteoglycans (HSPGs) in the extracellular matrix (ECM). ${ }^{2)}$ Several groups have reported detection of heparanase activity in various tumor cells, platelets and placenta. $^{2-6)}$ Expression of heparanase is correlated with the metastatic potential of tumor cells as well as that acquired by cells that are transfected with human heparanase cDNA. ${ }^{7}$ These findings indicate that heparanase-mediated degradation of heparan sulfate in the ECM might be critical during cell invasion associated with tumor metastasis and inflammation. ${ }^{7,8)}$

Remodeling of the ECM fosters development of cardiac hypertrophy and congestive heart failure. ${ }^{9,10)}$ Alterations of expression of matrix metalloproteinases (MMPs), another ECM-degrading proteinases, have been observed in diseased cardiac tissues. ${ }^{11-13)}$ These changes of MMP expression are thought to contribute to ventricular ECM remodeling, resulting in cardiac dysfunction. Nevertheless, changed cardiac expression of heparanase has not been investigated in cardiovascular diseases.

In $\beta$-adrenergic agonist-induced cardiac hypertrophy, heparanase expression might be induced in ventricular myocardium and might play an important role in cardiac hypertrophy development. We examined the gene expression of heparanase in rat myocardium following chronic treatment of isoproterenol (ISO) to test this hypothesis.

\section{MATERIALS AND METHODS}

Animals Male Wistar rats (7-9 weeks old; Clea Japan, Inc., Tokyo) were housed in standard cages. They were maintained on a standard laboratory diet and tap water and exposed to a $12 \mathrm{~h}$ light-dark cycle. Ambient temperature during the study was maintained at about $23^{\circ} \mathrm{C}$. All animals were cared for in accordance with guidelines for animal treatment of Kitasato University, which meets international guiding principles of laboratory animal care. The ISO-induced car- diac hypertrophy was performed as described previously ${ }^{14)}$ : ISO (Sigma Chemical Co., St. Louis, MO, U.S.A.) was administered intraperitoneally with twice-daily injections of $4 \mathrm{mg} / \mathrm{kg}$ for $4 \mathrm{~d}$. Control rats were injected with physiological saline $(1 \mathrm{ml} / \mathrm{kg})$ with the same regimen as that of ISO treatment. After $4 \mathrm{~d}$ of the experimental regimen, the hearts were excised with the use of sodium pentobarbital $(50 \mathrm{mg} / \mathrm{kg}$, i.p.) anesthesia. The hearts were separated into atrial and ventricular tissues.

Histological Analyses Ventricular tissues were fixed in $10 \%$ neutral formalin. The tissues were dehydrated and embedded in paraffin wax. For histological analyses, tissue sections $(4-5 \mu \mathrm{m})$ were stained with hematoxylin and eosin (HE). ${ }^{15)}$

Northern Blot Hybridization To prepare digoxigenin (DIG)-labeled cRNA probes, the polymerase chain reaction (PCR) primers for the genes for mouse heparanase (GenBank acc. no AY077467; 5'-AAGGAGTTCAAGAACAGCACCTA-3' and 5'-TCATATACAAGCAGCAATTTTGG-3'), for mouse MMP-2 (GenBank acc. no NM_008610; 5'-GTGACACCACGTGACAAGCC-3' and 5'-GCTCAGCAGCCCAGCCAGTC-3'), for mouse MMP-9 (GenBank acc. no. NM_013599; 5'-GACCTGAAAACCTCCAACCT-3' and 5'GAAGACGAAGGGGAAGACGC-3'), and for rat glyceraldehyde-3-phosphate dehydrogenase (GAPDH, GenBank acc. no M17701, 5'-GCTGATGCCCCCATGTTTG-3' and 5'-GCCATGAGGTCCACCC-3') were prepared. Preparation of DIG-labeled cRNA antisense and sense probes and Northern blot analyses were performed as described previously. ${ }^{16)}$

Statistical Analysis All data were presented as mean and S.E.M. Statistical significance was evaluated using Student's $t$-test; $p<0.05$ was considered significant.

\section{RESULTS}

Table 1 shows changes in body weight, ventricle weight and ventricle weight/body weight ratio in control and ISO- 
treated rats. Chronic treatment with ISO produced no change in body weight in either group. On the other hand, ventricle weight of the heart and ventricle weight/body weight ratio in ISO-treated rats were increased significantly by $22 \%$ and $25 \%$, respectively. Overt signs of congestive heart failure, such as pleural effusion and peripheral edema, were absent.

Histological differences between control and ISO-treated rats are portrayed in Fig. 1. Microscopic examination identified marked myocyte hypertrophy in ISO-treated rats in contrast to control rats.

Table 1. ISO-Induced Changes in Body Weight and Ventricle Weight

\begin{tabular}{lcc}
\hline \hline Parameters & Control & ISO \\
\hline Body weight $(\mathrm{g})$ & $272.7 \pm 4.9$ & $266.3 \pm 4.4$ \\
Ventricle weight $(\mathrm{mg})$ & $899 \pm 27$ & $1093 \pm 31^{* *}$ \\
Ventricle weight & $3.30 \pm 0.08$ & $4.11 \pm 0.11^{* *}$ \\
/body weight $(\mathrm{mg} / \mathrm{g})$ & &
\end{tabular}

Values are mean \pm S.E.M. of 10 rats in each group. ISO, isoproterenol. $* * p<0.01$ in comparison to the control group.

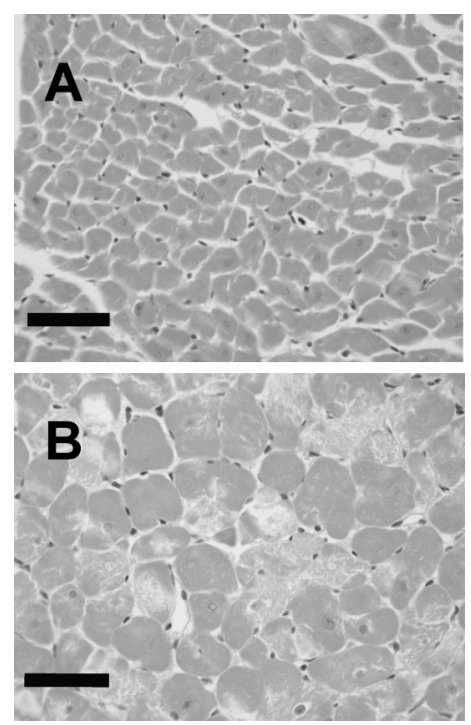

Fig. 1. Photomicrographs of Ventricular Tissue Sections Obtained from Control and ISO-Treated Rats

Representative photomicrographs of hematoxylin-stained and eosin-stained sections of rat ventricle treated without (A) or with (B) ISO. Scale bars represent $50 \mu \mathrm{m}$.
We used Northern blot hybridization to examine the myocardial heparanase gene expression following chronic treatment with ISO (Fig. 2). In addition, we examined myocardial MMP-2 and MMP-9 expression because myocardial MMP-2 increases in ISO-induced cardiac hypertrophy model. ${ }^{17)}$ The DIG-labeled antisense heparanase cRNA probe detected two mRNA transcripts in ventricles of control and ISO-treated rats, but the lower transcript was a very weak signal (Fig. 2A). In both groups, MMP-2 mRNA was also detected. On the other hand, expression of MMP-9 mRNA was observed in lung as a positive control, but not detected in the ventricles of control and ISO-treated rats. The intensity was determined by densitometric analysis of the autoradiogram. After normalization of each mRNA level to GAPDH mRNA, the bands corresponding to heparanase and MMP-2 mRNA were increased significantly, by approximately 1.8 -fold, in the ISO-treated rats compared with control rats (Fig. 2B).

\section{DISCUSSION}

This study has demonstrated that the gene expression of heparanase was induced in rat myocardium after chronic treatment with ISO. Furthermore, it was accompanied by increased gene expression of MMP-2, whereas MMP-9 expression was not induced. Pathological increases in heparanase mRNA expression have been reported in pancreatic cancer, ${ }^{18)}$ hepatocellular carcinoma, ${ }^{19)}$ esophageal carcinoma, ${ }^{20)}$ ovarian cancer ${ }^{21)}$ and gastric cancer. ${ }^{22}$ However, changes in expression of heparanase have not been investigated for cardiovascular diseases. This study demonstrates for the first time that expression of the gene for heparanase was induced in ventricular myocardium of the rat cardiac hypertrophy model. Prolonged treatment of rats using ISO has been widely used as a model of pharmacologically induced cardiac hypertrophy and heart failure. ${ }^{23,24)}$ In ISO-treated rats, the significant increase in the ventricle weight/body weight ratio observed in the present study revealed hypertrophic effects of chronic ISO treatment that are consistent with other reports. ${ }^{23,24)}$ Furthermore, histological analyses showed that chronic treatment of rats with ISO caused marked cardiomyocyte hypertrophy. These results indicate that chronic treatment with ISO caused cardiac hypertrophy in rats.

It has been reported that heparin-binding epidermal
A

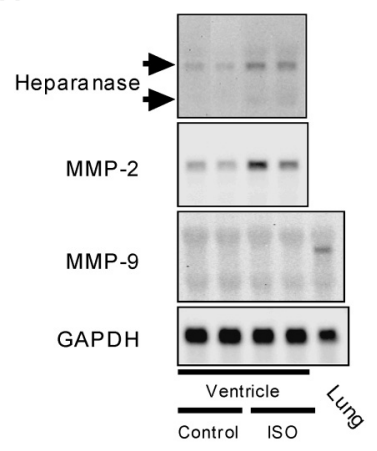

B

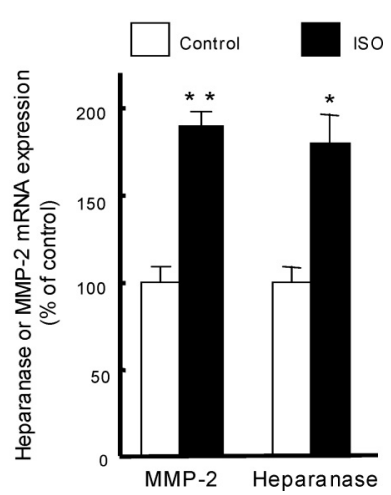

Fig. 2. Expression of Heparanase, MMP-2 and MMP-9 mRNA in the Ventricle of ISO-Treated Rats

Representative Northern blot image of heparanase, MMP-2, MMP-9 and GAPDH in the ventricles of control and ISO-treated rats (A). Densitometric analyses of heparanase, MMP-2 and MMP-9 mRNA levels (B). Levels were normalized to GAPDH. Data are given as the mean \pm S.E.M. $(n=6-8)$. $* p<0.05$ in comparison to the control group. $* * p<0.01$ in comparison to the control group. 
growth factor (HB-EGF) plays an important role in the induction of cardiac hypertrophy induced by $\beta$-adrenergic stimulation. ${ }^{25)}$ Shedding of HB-EGF on the surface of cardiomyocytes resulting from metalloproteinases activation and subsequent transactivation of epidermal growth factor receptor (EGFR) occurs when the cells are stimulated by G-protein-coupled receptor agonists such as $\beta$-adrenergic agonist, leading to cardiac hypertrophy. ${ }^{25)}$ Reportedly, HSPGs interact with heparin-binding growth factors such as HB-EGF, basic fibroblast growth factor, and vascular endothelial growth factor in the ECM. ${ }^{26,27)}$ Heparin-binding growth factors are released and activated when heparanase degrades the heparan sulfate side chains of HSPGs in the ECM. ${ }^{28)}$ Therefore, heparanase-mediated release of HB-EGF in myocardial ECM might be necessary to elicit transactivation of EGFR in cardiomyocytes. Furthermore, we found increased gene expression of MMP-2 in ventricles of ISO-treated rats. This result suggests that MMP-2 might be a candidate for HB-EGF shedding metalloproteinase. Although our results showed that the gene expression of heparanase was induced in the rat cardiac hypertrophy model, we could not ascertain whether cardiac hypertrophy is induced directly by heparanase and MMP-2. Time-dependent changes in myocardial heparanase and MMP-2 and the effect of heparanase and MMP-2 specific inhibitors in ISO-induced cardiac hypertrophy model remain undetermined.

Regulatory mechanisms underlying the induction of heparanase gene expression are not clear in this study. Reportedly, inducible transcription of human heparanase gene is mediated by activation of early growth response-1 (Egr-1) transcription factor in activated $\mathrm{T}$ cells. ${ }^{29)}$ Ogishima et al. ${ }^{30}$ reported that increased heparanase expression in prostate cancer tissues results from up-regulation of Egr-1. In addition, Egr-1 is reportedly overexpressed in hypertrophied hearts of mice treated with chronic ISO treatment, ${ }^{31)}$ and Egr-1 deficient mice revealed a blunted ISO-induced hypertrophy response. ${ }^{32}$ ) Therefore, the induction of myocardial heparanase gene expression might be mediated by increased expression of Egr-1 in ISO-induced cardiac hypertrophy.

It has been reported that MMP- 2 mRNA and activity are increased in cardiac tissue by $\beta$-adrenergic stimulation in vivo. ${ }^{17,33)}$ We also observed increased MMP-2 mRNA expression in the ventricles of ISO-treated rats. Numerous factors that can stimulate MMP expression have been identified, including transforming growth factor- $\beta^{34)}$ and angiotensin II. ${ }^{35)}$ Miura et al. ${ }^{17)}$ suggested that induction of MMP-2 in ISO-induced cardiac hypertrophy might be mediated in part by angiotensin II. Alternatively, $\beta$-adrenergic stimulation might cause production of a specific regulatory protein that directly or indirectly modulates MMP-2 gene transcription.

The myocardium comprises numerous cell types that include myocytes, fibroblasts, endothelial cells, and vascular smooth muscle cells. Cardiac fibroblasts, myocytes and endothelial cells express the MMP-2. ${ }^{36,37)}$ On the other hand, heparanase expression is restricted to platelets, neutrophils, monocytes, T-lymphocytes, and trophoblasts under normal conditions. ${ }^{38)}$ However, the present study does not directly address localization of heparanase in the heart. Further studies on localization of heparanase in the heart are required for better understanding of the role of heparanase in development of ISO-induced cardiac hypertrophy.
In conclusion, we suggest that heparanase might participate in the development of ISO-induced cardiac hypertrophy.

Acknowledgments This work was supported by grants to K. Kizaki: a Kitasato University Research Grant for Young Researchers, and a Grant-in-Aid for Encouragement of Young Scientists from the Ministry of Education, Culture, Sports, Science and Technology of Japan.

\section{REFERENCES AND NOTES}

1) Present address: Laboratory of Veterinary Physiology, Department of Veterinary Medicine, Faculty of Agriculture, Iwate University, Morioka, Iwate 020-8550, Japan.

2) Nakajima M., Irimura T., Di Ferrante D., Di Ferrante N., Nicolson G. L., Science, 220, 611-613 (1983).

3) Nakajima M., Irimura T., Di Ferrante D., Nicolson G. L., J. Biol. Chem., 259, 2283-2290 (1984).

4) Vlodavsky I., Fuks Z., Bar-Ner M., Ariav Y., Schirrmacher V., Cancer Res., 43, 2704-2711 (1983).

5) Goshen R., Hochberg A. A., Korner G., Levy E., Ishai-Michaeli R. Elkin M., de Groot N., Vlodavsky I., Mol. Hum. Reprod., 2, 679-684 (1996).

6) Freeman C., Parish C. R., Biochem. J., 330, 1341-1350 (1998).

7) Vlodavsky I., Friedmann Y., Elkin M., Aingorn H., Atzmon R., IshaiMichaeli R., Bitan M., Pappo O., Peretz T., Michal I., Spector L., Pecker I., Nat. Med., 5, 793-802 (1999).

8) Bartlett M. R., Underwood P. A., Parish C. R., Immunol. Cell Biol., 73, 113-124 (1995).

9) Olivetti G., Cigola E., Maestri R., Lagrasta C., Corradi D., Quaini F., Cardiovasc. Res., 45, 68-75 (2000).

10) Kim H. E., Dalal S. S., Young E., Legato M. J., Weisfeldt M. L., D'Armiento J., J. Clin. Invest., 106, 857-866 (2000).

11) Robert V., Besse S., Sabri A., Silvestre J. S., Assayag P., Nguyen V. T., Swynghedauw B., Delcayre C., Lab. Invest., 76, 729-738 (1997).

12) Li Y. Y., Feldman A. M., Sun Y., McTiernan C. F., Circulation, 98 1728-1734 (1998).

13) Peterson J. T., Li H., Dillon L., Bryant J. W., Cardiovasc. Res., 46, $307-315$ (2000)

14) Kizaki K., Momozaki M., Akatsuka K., Fujimori Y., Uchide T., Temma K., Hara Y., Biol. Pharm. Bull., 27, 1130-1132 (2004).

15) Yoshioka K., Enaga S., Taniguchi K., Fukushima U., Uechi M., Mutoh K., J. Comp. Pathol., 130, 92-98 (2004).

16) Kizaki K., Nakano H., Nakano H., Takahashi T., Imai K., Hashizume K., Reproduction, 121, 573-580 (2001).

17) Miura S., Ohno I., Suzuki J., Suzuki K., Okada S., Okuyama A., Nawata J., Ikeda J., Shirato K., J. Cardiovasc. Pharmacol., 42, 174181 (2003).

18) Kim A. W., Xu X., Hollinger E. F., Gattuso P., Godellas C. V., Prinz R. A., J. Gastrointest. Surg., 6, 167-172 (2002).

19) Xiao Y., Kleeff J., Shi X., Buchler M. W., Friess H., Hepatol. Res., 26, 192-198 (2003).

20) Mikami S., Ohashi K., Usui Y., Nemoto T., Katsube K., Yanagishita M., Nakajima M., Nakamura K., Koike M., Jpn. J. Cancer Res., 92, 1062-1073 (2001).

21) Ginath S., Menczer J., Friedmann Y., Aingorn H., Aviv A., Tajima K., Dantes A., Glezerman M., Vlodavsky I., Amsterdam A., Int. J. Oncol., 18, 1133-1144 (2001).

22) Endo K., Maejara U., Baba H., Tokunaga E., Koga T., Ikeda Y., Toh Y., Kohnoe S., Okamura T., Nakajima M., Sugimachi K., Anticancer Res., 21, 3365-3369 (2001).

23) Leon-Velarde F., Bourin M. C., Germack R., Mohammadi K., Crozatier B., Richalet J. P., Am. J. Physiol. Regul. Integr. Comp. Physiol., 280, R274-281 (2001).

24) Kimura H., Miyamoto A., Ohshika H., Life Sci., 53, PL171-176 (1993).

25) Asakura M., Kitakaze M., Takashima S., Liao Y., Ishikura F., Yoshinaka T., Ohmoto H., Node K., Yoshino K., Ishiguro H., Asanuma H., Sanada S., Matsumura Y., Takeda H., Beppu S., Tada M., Hori M., Higashiyama S., Nat. Med., 8, 35-40 (2002).

26) Wight T. N., Kinsella M. G., Qwarnstrom E. E., Curr. Opin. Cell Biol., 
4, 793-801 (1992).

27) Taipale J., Keski-Oja J., FASEB J., 11, 51—59 (1997).

28) Vlodavsky I., Bar-Shavit R., Ishai-Michaeli R., Bashkin P., Fuks Z., Trends Biochem. Sci., 16, 268-271 (1991).

29) de Mestre A. M., Khachigian L. M., Santiago F. S., Staykova M. A., Hulett M. D., J. Biol. Chem., 278, 50377-50385 (2003).

30) Ogishima T., Shiina H., Breault J. E., Tabatabai L., Bassett W. W., Enokida H., Li L. C., Kawakami T., Urakami S., Ribeiro-Filho L. A., Terashima M., Fujime M., Igawa M., Dahiya R., Clin. Cancer Res., 11, 1028-1036 (2005).

31) Saadane N., Alpert L., Chalifour L. E., Br. J. Pharmacol., 127, 11651176 (1999).

32) Saadane N., Alpert L., Chalifour L. E., Am. J. Physiol. Heart Circ.
Physiol., 278, H796-805 (2000).

33) Briest W., Holzl A., Rassler B., Deten A., Leicht M., Baba H. A., Zimmer H. G., Cardiovasc. Res., 52, 265-273 (2001).

34) Duivenvoorden W. C., Hirte H. W., Singh G., Clin. Exp. Metastasis, 17, 27-34 (1999).

35) Senzaki H., Gluzband Y. A., Pak P. H., Crow M. T., Janicki J. S., Kass D. A., Circ. Res., 82, 503-512 (1998).

36) Coker M. L., Doscher M. A., Thomas C. V., Galis Z. S., Spinale F. G., Am. J. Physiol., 277, H777-787 (1999).

37) Tyagi S. C., Kumar S., Glover G., J. Cell. Biochem., 58, 360-371 (1995).

38) Vlodavsky I., Friedmann Y., J. Clin. Invest., 108, 341-347 (2001). 